\title{
EVOLUCIÓN POLÍTICA Y PARTIDO REPUBLICANO. TRAYECTORIAS Y DISCURSOS DE LA NUEVA DERECHA PARTIDARIA CHILENA*
}

\author{
EVOLUCIÓN POLÍTICA AND PARTIDO REPUBLICANO. \\ DIRECTIONS AND DISCOURSES OF THE NEW \\ CHILEAN RIGHT
}

\author{
EVOLUCIÓN POLÍTICA ET PARTIDO REPUBLICANO. \\ PARCOURS ET DISCOURS DE LA NOUVELLE DROITE \\ DE PARTI CHILIENNE
}

\author{
Carlos Salvatore Durán Migliardi \\ Universidad Católica Silva Henríquez \\ cduranm@ucsh.cl \\ Gabriel Eduardo Rojas Roa \\ Universidad Católica Silva Henríquez \\ gabriel.rojas.r@ug.uchile.cl
}

Resumen: A partir de la descripción del contexto sociopolítico chileno de la última década, este artículo analiza los orígenes, ejes discursivos y configuración de la identidad partidaria de Evolución Política y Partido Republicano, partidos de reciente creación y que se inscriben en el contexto regional de adaptación y cambio de la derecha latinoamericana. La hipótesis central es que ambos partidos surgen de la búsqueda para enfrentar de formas distintas los desafíos generados a la derecha como resultado de su retorno al gobierno en 2010 y del efecto dislocatorio de las movilizaciones sociales de 2011.

Palabras claves: Chile; derecha política; partidos políticos; discurso político; cambio político.

Abstract: Based on the description of the Chilean sociopolitical context over the last decade, this article analyzes the origins, key discourses and con-

* Artículo realizado como parte del proyecto FONDECYT / ANID 1191491, Chile. 
figuration of the party identity of Evolución Política and Partido Republicano, parties of recent creation that belong to a regional context of renewal of the Latin American Right. The central hypothesis is that both parties arise from the search to face in different ways the challenges generated by the Right as a result of their return to government in 2010 and the dislocating effect of the social mobilizations of 2011.

Keywords: Chile; political right; political parties; political discourse; political renewal.

\section{Traducción de Fionn Petch, CM Idiomas}

RÉsumÉ: À partir de la description du contexte sociopolitique chilien de la dernière décennie, cet article analyse les origines, les axes discursifs et la configuration de l'identité partisane d'Evolución Política et de Partido Republicano, partis récemment créés qui s'inscrivent dans le contexte régional d'adaptation et changement de la droite latino-américaine. L'hypothèse centrale est que les deux partis sont nés de la recherche d'une façon d'aborder de façons différentes les défis posés à la droite par suite de son retour au pouvoir en 2010 et de l'effet de dislocation des mobilisations sociales de 2011.

Mots-cléf: Chili ; Droit politique ; partis politiques ; discours politique ; changement politique.

Traducción de Rafael Segovia, CM Idiomas

Fecha de recepción: septiembre de 2020. Fecha de aceptación: julio de 2021. 


\section{INTRODUCCIÓN}

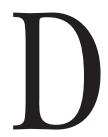
esde finales del siglo xx, la hegemonía alcanzada en América Latina por el Consenso de Washington y su agenda de reformas se agotaba. ${ }^{1}$ De ahí en adelante, distintas experiencias de gobiernos progresistas y de izquierda marcaron el mapa político de la región. En países como Venezuela, Argentina, Bolivia, Ecuador, Brasil, El Salvador o Uruguay, gobiernos identificados con una nueva agenda "antineoliberal”, encabezaron procesos que dejaban atrás el ciclo anterior y generaban, en consecuencia, una crisis de los sectores partícipes del heterogéneo mundo de las derechas. ${ }^{2}$ Una crisis que promovió la activación de un proceso de reinvención cuyas resultados derivaron, en algunos casos, en el surgimiento de nuevas organizaciones políticas. ${ }^{3}$

A contrapelo de estas tendencias, en el caso chileno la readaptación y cambio orgánico de la derecha acontece en un marco distinto, caracterizado por su retorno al gobierno tras dos décadas de hegemonía centroizquierdista expresada

${ }^{1}$ Sobre el carácter del giro a la derecha y su articulación con la agenda neoliberal existe una amplia discusión. Ha sido frecuente, por ejemplo, su asociación con la tradición populista latinoamericana. Sobre esto, véase René Mayorga, "Antipolítica y Neopopulismo en América Latina”, Relaciones, 161. Serie Convivencias (xv). Montevideo, Periódica S.R.L. Para una crítica historicista a la asociación entre populismo y neoliberalismo véase Carlos Vilas, "¿Populismos reciclados o neoliberalismo a secas? El mito del neopopulismo latinoamericano", Revista Venezolana de Economía y Ciencias Sociales, vol. 9, núm. 3, (2003), pp. 13-36.

2 Para una discusión sobre el "giro a la izquierda", véase Soledad Stossel, "Giro a la izquierda en la América Latina del siglo xxi: revisitando los debates académicos", Polis, vol. 13, núm. 39 (2014), y Steven Levistky y Kenneth M. Roberts (eds.), The Resurgence of the Latin American Left, Baltimore, The Johns Hopkins University Press, 2011.

${ }^{3}$ Para una aproximación al tema de las nuevas derechas latinoamericanas véase Maristella Svampa, "Posprogresismos, polarización y democracia en Argentina y Brasil", Nueva Sociedad, 284 (2019), pp. 121-134; Juan Pablo Luna y Cristóbal Rovira (eds.), The resilience of the Latin American Right, Baltimore, The Johns Hopkins University Press, 2014. 
en cuatro gobiernos consecutivos de la Concertación por la Democracia. ${ }^{4}$ ¿Cuáles son las causas que explican esta aparente paradoja?

El retorno de la derecha al gobierno en 2010 modificó sustantivamente las formas de acción política del sector, toda vez que obligó a la derecha a asumir tareas gubernativas que implicaban convivir con la diversidad de demandas propias de todo escenario democrático, hacerse cargo de la agenda pública y demostrar que se encontraba capacitada para gobernar en democracia y ya no en una dictadura, tal y como ocurrió durante el periodo 1973-1990.

Todo ello abrió paso a una serie de debates expresivos de la tensión entre la conservación de su identidad histórica y programática, por un lado, y las tareas propias de ser gobierno, por el otro. A estas dificultades se sumó el desafío hegemónico que significó el acelerado proceso de politización generado por movilizaciones sociales y estudiantiles que, como veremos, produjeron a partir de 2011 una fuerte dislocación no sólo de la derecha sino de todo el campo político. ${ }^{5}$

Es precisamente en el marco de este doble proceso de retorno al gobierno e intensas movilizaciones sociales que se concreta el proceso de adaptación y cambio orgánico de la derecha chilena que nos proponemos abordar en este artícu-

${ }^{4}$ La "Concertación", fundada en 1988 para organizar la exitosa disputa plebiscitaria contra Pinochet, constituye una de las coaliciones políticas más exitosas de la historia latinoamericana. Para una aproximación a su historia, véase Mireya Dávila, "Tecnocracia y democracia en el Chile contemporáneo: el caso de los gobiernos de la Concertación (19902010)", Revista de Sociología, 24 (2010), pp. 199-217.

${ }^{5}$ Las movilizaciones estudiantiles de 2011, centradas en la demanda central por la gratuidad universitaria, constituyeron un acontecimiento sumamente relevante en la deriva del proceso social y político chileno. Sobre esto, véase Carlos Durán, "El acontecimiento estudiantil y el viraje del proceso sociopolítico chileno", Observatorio social de América Latina, xIII, 31, (2012), pp. 39-60; Octavio Avendaño, "Fracturas y representación política en el movimiento estudiantil: Chile 2011", Última década, núm. 41, (2014), pp. 41-68; Francisco Figueroa, Llegamos para quedarnos. Crónicas de la revuelta estudiantil, Santiago, LOM, 2013. 
lo, centrando la atención en el surgimiento del Partido Republicano -PR- y Evolución Política -Evópoli-, nuevos referentes que llegan a diversificar la oferta político-programática de dicho sector.

Desde una perspectiva sociohistórica exponemos los orígenes, ejes discursivos y configuración de la identidad diferencial de ambos partidos. Nuestra hipótesis central es que tanto Evópoli como el PR surgen de la búsqueda compartida por enfrentar los desafíos generados como resultado tanto del retorno de la derecha al gobierno (2010) como del efecto de las movilizaciones sociales de 2011. Es decir, constituyen la respuesta a una coyuntura crítica ${ }^{6}$ que generó efectos no sólo sobre la composición actoral y discursiva de la derecha chilena sino también sobre el campo político-institucional en su conjunto. ${ }^{7}$

${ }^{6}$ En concordancia con la teoría del discurso de Laclau, entendemos por coyuntura crítica el conjunto de eventos que tienen como resultado la alteración, en un lapso temporal acotado, de una determinada configuración político-discursiva y que tiene como una de sus consecuencias eventuales la de promover el surgimiento de nuevos actores y/o organizaciones políticas. Sobre esto, véase Entesto Laclau, La razón populista, Buenos Aires, FCE, 2005. Para una definición de coyuntura crítica similar a la acá planteada, aunque con un acento en la mediana duración histórica, véase Ruth Collier y David Collier, Shaping the political arena: Critical junctures, the labor movement, and regime dynamics in Latin America, Notre Dame, University of Notre Dame Press, 2002. Para la descripción somera de teorías alternativas respecto a los procesos de renovación partidaria véase Juan Abal Medina, "El surgimiento de los partidos políticos, una propuesta interpretativa", en Juan Abal Medina (comp.), Los senderos de la nueva izquierda partidaria, Buenos Aires, Prometeo, 2006.

${ }^{7}$ Para los efectos de este trabajo, y en concordancia con la definición de Pierre Bourdieu, entendemos por campo político 1) un espacio de relativa autonomía, 2) con reglas y actores característicos y 3 ) en el que se disputa la posesión y/o resistencia frente al poder legitimado socialmente. Para nuestro caso particular, un espacio en el cual se gesta una disputa entre distintas organizaciones políticas por la producción de una condición hegemónica capaz de disputar su sentido y dirección. Sobre esto, véase Pierre Bourdieu, "Algunas propiedades de los campos", en Campo de poder, campo intelectual, Buenos Aires, Montressor, 2003. 
Junto a ello, sostenemos que ambas organizaciones siguen cursos distintos en cuanto a la producción de su identidad y estrategia discursiva: mientras Evópoli opta por una estrategia de naturaleza renovadora, el PR opta por configurarse como un espacio de restauración de la identidad tradicional de la derecha chilena.

Son precisamente estas diferencias las que permiten comprender la forma en que ambos partidos se ubican en el campo político, el lugar que en ellos asume el problema de la desigualdad social y la forma en que se relacionarán tanto con la derecha tradicional como con el segundo gobierno de Piñera (2018-2022) y el proceso constituyente, actualmente en curso en Chile. Pese a ser tendencialmente intensas, son diferencias que se vinculan con un conjunto de elementos compartidos por ambas organizaciones sobre los cuales nos referiremos a lo largo de este artículo, entre los que se encuentran: 1) su raíz sociológica, política y culturalmente común, 2) su adhesión a algunos principios doctrinarios compartidos tales como la libertad económica, 3) su relación de adversarialidad con el espacio político de la izquierda chilena y 4) sus alianzas electorales tales como la acontecida en las recientes elecciones para la Convención Constituyente constituida en junio de 2021.

Para la elaboración de este trabajo procedimos a la revisión y sistematización de un numeroso conjunto de fuentes referidas a los procesos de constitución, los contenidos programáticos y los ejes discursivos de las dos organizaciones aquí estudiadas. Específicamente, nos centramos en: a) los manifiestos fundacionales, las declaraciones de principios y los programas de gobierno de ambos partidos y b) las declaraciones y entrevistas realizadas por sus principales dirigentes y publicadas en medios de prensa de circulación nacional durante el periodo 2012-2019, para el caso de Evópoli , y 20162019 para el caso de J A-Kast y el PR.

Una vez realizada la recopilación y sistematización, analizamos y agrupamos la información en función de los siguientes elementos propios de lo que entendemos como discurso 
político: construcción del nosotros partidario (narrativas del origen partidario), significantes privilegiados (ideas-fuerza), contenidos (aspectos programáticos) y construcción de adversarialidad (exterior-constitutivo). ${ }^{8}$

Finalmente, y luego de haber saturado cada una de las dimensiones observadas, procedimos a la selección de un conjunto acotado de enunciados representativos de las significaciones propias de cada uno de los partidos y que presentamos en este trabajo.

Este artículo se organiza de la siguiente manera: en la primera parte reconstruimos el contexto de emergencia de las organizaciones y sus procesos de formación para luego, en la segunda parte, describir sus configuraciones discursivas y analizar las relaciones de identidad y diferencia posibles de observar, tanto entre Evópoli y PR como entre estas organizaciones y los partidos de la derecha política tradicional chilena.

El artículo concluye con algunas observaciones relativas a la deriva futura de estas organizaciones en el marco del proceso constituyente recientemente abierto en Chile.

\section{LA DERECHA CHILENA: ENTRE LA TRADICIÓN Y LA INNOVACIÓN}

Los 17 años de dictadura militar transformaron profundamente a la sociedad chilena. Junto a los cambios económicos, sociales y culturales, el paisaje político se modificó sustantivamente. En el caso específico de la derecha política, ${ }^{9}$ su proce-

${ }^{8}$ Por discurso político entendemos un conjunto de enunciados comunicativos compuestos por elementos que se encuentran contingentemente articulados entre sí, que definen la identidad de un grupo que participa de la disputa por el poder político y que integra una totalidad parcial de sentido. Una organización política, en consecuencia, sería bajo esta definición una unidad potencial aunque no necesariamente portadora de un discurso político distintivo. Para un abordaje en profundidad de esta definición, véase Ernesto Laclau, op. cit.

${ }^{9}$ Obviando la extensa discusión sobre esta categoría, para los efectos de este artículo entenderemos por derecha política 1) un espacio en cuyo 
so de reconversión inició con la temprana crisis de su referente orgánico anterior -el Partido Nacional-y el surgimiento de diversas organizaciones políticas, entre las que destacaron dos que terminarían convirtiéndose en la expresión consolidada de la derecha partidaria: la Unión Demócrata Independiente (UDI) y Renovación Nacional (RN).

Especialmente intensa es la ruptura generada por la UDI respecto a la tradición de la derecha chilena. Desde la acelerada superación de su matriz nacionalista hasta su fuerte trabajo de inserción en sectores urbano-populares, su férrea disciplina interna y una homogeneidad ideológica muy marcada, este partido fue generando una particular articulación entre liberalismo económico y conservadurismo valórico, junto a una visión restrictiva de la democracia. Cuestión distinta ocurría en RN, un partido creado a partir de la inserción de diversas tradiciones ideológicas y en cuyo seno conviven nuevos estilos, liderazgos y agendas temáticas con la tradición y diversidad de la vieja derecha. Esto redundaba en la existencia de un partido alejado del carácter monolítico de la UDI pero, por lo mismo, afectado por múltiples y recurrentes tensiones. ${ }^{10}$

Durante el periodo posdictatorial, ambos partidos marcaron posiciones diferenciadas en cuanto a su relación con

interior conviven diferentes expresiones orgánicas e inorgánicas, 2) que disputan el poder político, 3) comparten la consideración de ciertas desigualdades sociales como naturales, justas y/o necesarias, aun cuando ellas puedan referir a distintos ámbitos de la vida social y 4) se disponen antagónicamente a la izquierda. Para una descripción sumaria de las diversas estrategias nominativas de esta categoría, véase Juan Pablo Luna y Cristóbal Rovira, op. cit. Sobre la centralidad de la "igualdad" como significante clave para la distinción entre izquierda y derecha, véase el texto clásico de Norberto Bobbio, Derecha e izquierda. Razones y significados de una distinción política, Madrid, Taurus, 1996.

${ }^{10}$ Para una descripción histórica de las continuidades y ruptura de la derecha chilena, véase Joaquín Fernández y Sebastián Rumié, "Las transformaciones de la derecha chilena: desafíos, adaptaciones y renovaciones (1932-2010)", en Stéphanie Alenda (ed.), Anatomía de la derecha chilena. Estado, mercado y valores en tiempos de cambio, Santiago, FCE, pp. 43-86. 
los distintos gobiernos democráticos. Mientras la UDI operó como bastión defensivo del legado de la dictadura optando por una estrategia de oposición intransigente, RN ensayó fórmulas de negociación y producción de acuerdos, que a inicios del proceso de normalización democrática se materializaron, por ejemplo, en su participación en las reformas tributaria y laboral, medidas que resultaron clave para el éxito del gobierno de Patricio Aylwin. ${ }^{11}$

Pero estas diferencias estaban lejos de representar formas antagónicas de construcción partidaria. En primer lugar, porque ambos partidos privilegiaron desde un principio la construcción de estructuras orgánicas institucionalizadas por sobre el personalismo, situación que las identifica como parte de una derecha típicamente partidaria; ${ }^{12}$ en segundo lugar, porque no se propusieron un retorno a las tradiciones ideológicas de la derecha preautoritaria y, por último, porque se centraron programáticamente en la defensa del proyecto refundacional de la dictadura. ${ }^{13}$

${ }^{11}$ Esta disposición negociadora de RN, coincidente con la estrategia concertacionista, dio origen a lo que se conoció como "la democracia de los acuerdos", modelo de normalización democrática caracterizado por su naturaleza fuertemente consociativa. Sobre este tópico, véase Carlos Durán, "Chile vuelve al vecindario: de la complacencia al malestar", en Álex Caldera y Armando Chaguaceda (coords.), Democracia en América Latina: entre el ideal utópico y las realidades políticas, México, D.F., Fontamara, 2016, pp. 187-209.

${ }^{12}$ Históricamente y en comparación con el contexto latinoamericano, la derecha partidaria chilena se caracteriza por su fuerte institucionalización y estabilidad. Si bien sus organizaciones no han sido ajenas al relevamiento de liderazgos independientes, los partidos políticos siempre han tenido un rol ordenador y han concentrado las preferencias ciudadanas. Sobre esto, véase Scott Mainwaring y Mariano Torcal, "La institucionalización de los sistemas de partidos y la teoría del sistema partidista después de la tercera ola democratizadora", América Latina Hoy, 41 (2005), pp. 141-173.

${ }^{13}$ Estos rasgos en común son los que permiten identificar a la UDI y RN como pertenecientes al tipo de derecha que Luna y Rovira identifican como 1) electoral, 2) partidaria y 3) posautoritaria. Véase sobre esto Juan Pablo Luna y Cristóbal Rovira, op. cit., pp. 348-353. 
Subsidiada por la relevante presencia de una derecha no partidaria alojada en las FFAA y el empresariado, así como por la vigencia de una institucionalidad política altamente favorable, la derecha partidaria chilena contó en definitiva con una fuerte capacidad de intervención en el contexto político de normalización democrática. Si bien su condición opositora no permite asumirla como expresión ejemplar del giro neoliberal de la década de 1990 -protagonizado, por ejemplo, por Salinas en México, Menem en Argentina o Fujimori en Perú-, su nivel de relevancia en la dirección del proceso político la ubica como un sector ampliamente exitoso e incidente en el destino político del país durante aquel periodo.

De esta forma, la principal alternativa política que se perfila frente a la centroizquierda es la de una derecha que goza de una potencia electoral estable, con un proyecto común más allá de las diferencias tácticas. Por lo mismo, mientras países como Venezuela, Ecuador, Bolivia, Argentina, Uruguay o Brasil protagonizaban el denominado "giro a la izquierda", en Chile la derecha se consolidaba y limitaba las posibilidades de desarrollo de una agenda de superación del neoliberalismo. Liderada primero por la retórica "cosista" del dirigente UDI Joaquín Lavín ${ }^{14}$ y luego por el liderazgo liberal tecnocrático de Sebastián Piñera, durante la primera década del siglo xxi la derecha fue generando las condiciones para asumir el gobierno y presentarse como una alternativa de recambio hasta que, en las elecciones de 2009, logra retornar al ejecutivo tras dos décadas en la oposición y luego de más de 50 años sin haber ganado una elección presidencial. ${ }^{15}$

${ }^{14} \mathrm{El}$ apelativo "cosismo" fue usado para identificar un estilo desprendido de la identidad clásica de la derecha y vinculado a lo que se identificaba como "los problemas concretos de la gente". Encarnado en la figura del líder UDI, Joaquín Lavín, le significó a la derecha un sustantivo crecimiento electoral que estuvo a punto de llevarla a ganar las elecciones del año 2000. Sobre esto, véase Carlos Durán, "Campo político-institucional y procesamiento del malestar social en Chile, 1999-2009”, Izquierdas, núm. 40, (2018), pp. 8-12.

${ }^{15}$ Luego de haber obtenido $44 \%$ de la votación en la primera vuelta electoral, Piñera logra imponerse finalmente con $51.65 \%$ de los votos en 
Encabezada por Piñera, la coalición derechista le asestaba a la Concertación una derrota de la cual no pudo reponerse, abriendo paso a lo que se veía como un auspicioso periodo de gobierno caracterizado por 1) la cohesión de sus partidos, 2) una maciza presencia en el ámbito legislativo y en los gobiernos locales, 3) un amplio apoyo electoral y 4) un ciclo económico favorable que permitía avanzar sin mayores obstáculos en la agenda programática propuesta al país.

Los primeros meses de gobierno fueron halagüeños. La necesidad de concentrar la gestión en las tareas de reconstrucción tras el terremoto y tsunami de febrero de 2010 embonaba con un posicionamiento que había hecho de la eficiencia el principal atributo del nuevo gobierno. El accidente y posterior rescate de los 33 mineros atrapados en una mina nortina constituyó el epítome de este relato: la puesta en funcionamiento de una eficiente articulación público-privada, con laboriosidad gubernativa y todas las energías puestas en un objetivo común, constituían la ilustración perfecta de un estilo que, bajo la consigna "la nueva forma de gobernar", había impulsado la derecha desde la campaña electoral de 2009.16

la segunda vuelta. Éste y los resultados electorales que más adelante iremos señalando han sido obtenidos de los registros históricos del Servicio Electoral de Chile (Servel), https://historico.servel.cl/

${ }^{16}$ Ilustrativa del interés por poner "la técnica por sobre la ideología" como sello distintivo de la derecha en el gobierno, esta consigna implicaba, siguiendo a Robert Funk, cuatro aspectos: "el primero [...] donde el presidente sea 'todo terreno', que esté presente 'las 24 horas del día por 7 días a la semana'". El segundo punto corresponde al "fin de cuoteo político", de terminar las "malas prácticas" propias del desgaste que sufrió la Concertación después de 20 años: "El Estado no será más un botín de guerra ni será capturado por los operadores políticos. Los cargos serán asignados por capacidad y experiencia y no por favores". En otras palabras "Gobernar con los mejores". El tercer punto se refiere a "reimplantar la cultura de hacer las cosas bien para la gente y no para las noticias de la televisión", y por último -el punto más difuso quizás- es el de "imponer el sentido de la urgencia", específicamente en el actuar del gobierno en cuanto a los "principales temas" que aquejan al país". Robert Funk, "El relato político en el primer año del gobierno de Piñera Política", Revista de Ciencia Política, vol. 49, núm. 2 (2011), p. 156. 
Pese al buen pie inicial, dentro de la coalición gobernante se iba gestando un conflicto entre los sectores tradicionales y aquellos que sostenían la necesidad de renovación. El eje del debate lo constituía el dilema entre mantener el sello tradicional del sector o producir un aggiornamento y adaptación a los desafíos que implicaba ser gobierno y responder a demandas sociales cada vez más diversas.

Un hito importante en este debate fue la propuesta emitida por el entonces ministro de Interior y militante de Renovación Nacional, Rodrigo Hinzpeter, de conformación de una "nueva derecha" que pudiera abrirse hacia temas valóricos tradicionalmente tabúes, disputar el centro político, distanciarse decididamente de la dictadura militar y repensar el rol del Estado. ${ }^{17}$

Desde la vereda opuesta, estas propuestas eran interpretadas como una concesión excesiva y gratuita al "progresismo", una incorporación impropia de "ideas ajenas" y un debilitamiento de los componentes identitarios de la derecha. Abrir la agenda programática hacia tópicos que no eran propios del sector constituía, para sectores agrupados principalmente en la UDI, un peligro serio de "desperfilamiento" y derrota cultural frente a la izquierda. Mantener el lugar era una obligación. ${ }^{18}$

Junto a este debate, surgió también un diagnóstico autocrítico referido a la ausencia de un "relato" capaz de movilizar,

17 Para una descripción del debate generado en torno a la "nueva derecha” véase Augusto Varas, El gobierno de Piñera (2010-2014), Catalonia, Santiago, 2013, pp. 75-102.

18 "La gente votó mayoritariamente por la Alianza y quería un cambio, porque veía en nosotros mayor seguridad, la dignificación de la persona, el establecimiento de una cultura de la responsabilidad. Eso es lo que nosotros podríamos decir que es nuestro ethos, nuestro sustrato cultural, ideas que no hemos logrado transmitir"; Jovino Novoa, exsenador y vicepresidente de la UDI, Revista Qué pasa, 17 de junio de 2011, citado en Andrea Gartenlaub, "Trayectorias, permanencias y continuidades de la competencia política y de los perfiles ideológicos de los partidos de derecha chilenos en la posdictadura", tesis para optar al grado académico de doctora en Ciencias Sociales, Santiago, Universidad de Chile, 2018, p. 214. 
generar sentido e ir más allá del sello tecnocrático-empresarial que había asumido el gobierno. Abierto por el dirigente UDI, Pablo Longueira, este diagnóstico destacaba los problemas de una derecha demasiado apegada a los dogmas económicos y desprovista de la capacidad estratégica de generar un discurso que pudiera movilizar y generar adhesión de las capas medias y los sectores populares.

Pero las dificultades en el flanco interno fueron desplazadas por los crecientes conflictos sociales que progresivamente fueron tensionando al gobierno. A las recurrentes acusaciones de conflicto de interés generadas por los vínculos entre funcionarios gubernamentales y el mundo empresarial, se fueron sumando expresiones de protesta socioambientales y territoriales que desdibujaron la fortaleza inicial del gobierno, lo que produjo hacia fines de su primer año más de algún inconveniente y cambios ministeriales. Así, el debate de la coalición se complementaba con una situación política adversa a la cual había que responder.

Hacia abril de 2011, estas dificultades se agudizaron y trascendieron ampliamente los márgenes del debate doctrinario. A partir de esa fecha, las movilizaciones estudiantiles coparon las calles de las principales ciudades del país, instalando en la agenda un conjunto de reivindicaciones sociales que modificaron dramáticamente el escenario social y político.

Las movilizaciones de 2011 produjeron un punto de inflexión en el proceso político chileno al reinstalar abruptamente el debate en torno a la vigencia y legitimidad del modelo económico-social y formar un campo antagónico que derivó en un proceso de repolitización. El campo de disputa se resignificó aceleradamente y la otrora ofensiva posición de una derecha exitosa giró al lugar de defensa ideológica de un modelo cuyas bases de sustentación se encontraban -por primera vez desde el retorno a la democracia- seriamente amenazadas. Tal y como indica un intelectual de la derecha chilena, ocurrió en definitiva que: "La transición se caracterizó por una incesante búsqueda de consensos, y por la convicción según la cual el crecimiento económico podría resolver 
buena parte de nuestros problemas. No obstante, a partir del 2011 las categorías empezaron a cambiar: el lucro fue demonizado, el modelo paso a ser objeto de crítica y, en general, la confianza en las instituciones políticas, económicas y religiosas se dañó gravemente". ${ }^{19}$

Paradojalmente, y a diferencia de lo ocurrido en el contexto regional, en el caso chileno fue el retorno de la derecha al gobierno y no su pérdida lo que puso en marcha una crisis política, estratégica e identitaria que abriría las puertas para la diversificación de su oferta política y la apertura de un debate, aún en ciernes, acerca de la vigencia del proyecto histórico asumido como propio a partir del 11 de septiembre de $1973 .{ }^{20}$

\section{Evolución política}

A pocas semanas de asumir su primer gobierno en marzo de 2010, el presidente Piñera nombró un gabinete caracterizado por un fuerte sesgo tecnocrático, entre cuyos miembros destacaba -en la cartera de Desarrollo Social- el economista de 32 años Felipe Kast, quien por ese entonces se desempeñaba como investigador del Instituto Libertad y Desarrollo, centro de pensamiento ligado a la UDI.

${ }^{19}$ Daniel Mansuy, Nos fuimos quedando en silencio. La agonía del Chile de la transición, Santiago, Instituto de Estudios de la Sociedad, 2016, p. 18.

${ }^{20}$ El debate político generado en la derecha a partir de 2011 también tuvo su correlato en el ámbito intelectual, desde donde se ha generado una amplia producción en torno a las continuidades, rupturas y crisis de este sector político. Para una exposición del marco de estos debates, véase Daniel Mansuy, op. cit.; Hugo Herrera, La derecha en la crisis del bicentenario, Santiago, Ediciones UDP, 2014; Luis Larraín, El regreso del modelo, Santiago, Libertad y Desarrollo, 2012. Para una descripción del reimpulso de los centros de pensamiento de la derecha como fruto de este contexto véase Sthepanie Alenda, Andrea Gartenlaub y Karin Fischer, "Ganar la batalla de las ideas: el rol de los think tanks en la configuración de la nueva centro-derecha chilena”, en Stéphanie Alenda (ed.), op. cit., pp. 119-156. 
Pese a su profunda cercanía biográfica y cultural con la UDI ${ }^{21}$ Felipe Kast se fue perfilando como una figura independiente, representativa de la "nueva camada" de profesionales que, provenientes del mundo privado, la iniciativa empresarial o el voluntariado religioso, se integraban al nuevo gobierno o miraban con cercanía su estilo y objetivos.

Junto a ello, su perfil realizador y juvenil fue generando una referencialidad en un segmento sociogeneracional identificado con la derecha, pero alejado de sus identidades partidarias. Jóvenes profesionales de sectores sociales medios y altos, socializados en colegios de elite, con experiencia en voluntariado y partícipes de un mundo social de pertenencia claramente distinguible, veían en el ministro una figura moderna, representativa de un proceso de renovación de las formas y contenidos de la derecha tradicional. ${ }^{22}$

Sin embargo, a poco más de un año de haber asumido su puesto, el ministro Kast renunció para convertirse en delegado presidencial para campamentos y aldeas de emergencia en el marco del proceso de reconstrucción posterremoto 2010. Esto hasta que, junto a un grupo de independientes y

${ }^{21}$ Felipe Kast es hijo del fallecido exministro de Pinochet, Miguel Kast, uno de los principales protagonistas de la implementación de la política social y laboral del régimen militar desde Odeplan y el Ministerio del Trabajo, respectivamente. Destacado miembro del núcleo fundacional de la UDI, representaba ejemplarmente las dos corrientes que inspiran a esta organización: como miembro activo del movimiento gremialista, por una parte, y egresado de la Escuela de Economía de la Universidad de Chicago, por la otra, reflejaba la imbricación entre conservadurismo valórico y neoliberalismo que da origen al así llamado "Chicago-gremialismo" que forma el núcleo base de la Udi. Sobre esto, véase Víctor Muñoz, Historia de la UDI. Generaciones y cultura política (1973-2013), Santiago, Ediciones Universidad Alberto Hurtado, 2016, pp. 66-83.

${ }^{22}$ El concepto de "mundo social de pertenencia" es utilizado por Vommaro en referencia a los aspectos que definen el activo militante de Propuesta Republicana, partido argentino cuyas características se asemejan fuertemente al perfil que, con el correr de los años, irá adquiriendo Evópoli. Véase sobre esto Gabriel Vommaro, "Propuesta republicana y sus mundos de pertenencia: una perspectiva sociocultural de la nueva centro-derecha argentina”, en Stéphanie Alenda (ed.), op. cit, pp. 301-322. 
miembros del gobierno de Piñera, con quienes había fundado en 2011 el centro de estudios "Horizontal", anunció el lanzamiento del movimiento Evolución Política, que se materializó el 12 de diciembre de 2012 en un pequeño acto ampliamente cubierto por la prensa nacional. ${ }^{23}$

El diagnóstico a partir del cual F. Kast decidía conducir la formación de un nuevo movimiento político venía anunciándose desde su instalación misma como ministro: durante años se iba engrosando una generación de profesionales afines a las ideas de la derecha, con "vocación social", disponibles para el trabajo colectivo pero indispuestos frente a la política y las organizaciones existentes por aquel entonces. Una brecha generacional que, era su convicción, debía ser cubierta con la creación de una nueva organización:

Una de las virtudes de nuestra generación es que se tomó lo social muy de cerca en las poblaciones, pero que ha despreciado la política. El susto que tengo es que esta generación no se tome en serio este tema, que abandonemos, y que esto sea una experiencia temporal en el Ejecutivo y que no se inserten en los partidos políticos. Es muy cómodo tener una pega en el gobierno, y es mucho menos cómodo, más desafiante, más relevante, el tomarte el tema político en serio. ${ }^{24}$

Ya en su manifiesto fundacional quedaba patente el sello renovador de Evópoli. En él, el nuevo movimiento se presentaba como una propuesta que buscaba aportar al crecimiento de la derecha hacia sectores, ideas y sensibilidades hasta entonces desatendidas:

${ }^{23}$ Para una descripción detallada del proceso de emergencia de Evópoli, véase Alenda, le Foulon y del Hoyo: "Evolución política y la renovación liberal en Chile”, en Stéphanie Alenda (ed.), op. cit., pp. 157-189.

24 "Felipe Kast, ministro de Planificación: 'La izquierda no valora la movilidad social'", The Clinic, 20 de octubre 2010, https://www.theclinic. $\mathrm{cl} / 2010 / 10 / 24 /$ felipe-kast-ministro-de-planificacion- $\%$ E2\%80\%9Cla-izquierda-no-valora-la-movilidad-social-les-cuesta-que-el-esfuerzo-tepremie $\% \mathrm{E} 2 \% 80 \% 9 \mathrm{D} /$ 
Este movimiento, si bien no desconoce su cercanía con el gobierno actual, aspira a convocar una representación más amplia. En un ambiente político más fluido hay espacio para reordenar el espectro político tradicional. Chile ha vivido durante gran parte de su historia democrática un clima polarizado. Los actuales partidos están todavía fuertemente marcados por esa historia. [...] hay un importante espacio político que no es cubierto por los dos partidos de la coalición, es decir hay votantes que se dejan convencer por los candidatos presidenciales de la coalición pero no por sus partidos. ${ }^{25}$

Una vez constituido como movimiento, el crecimiento y protagonismo de Evópoli al interior de la alianza oficialista fue veloz. A pocos meses de su fundación, logró incorporarse al proceso electoral de 2013, luego participó en la fundación de un nuevo conglomerado de partidos -"Chile Vamos"-, en las elecciones primarias de dicho conglomerado y en la elección presidencial y parlamentaria de fines del mismo año. En esas elecciones, se logró elegir a Felipe Kast con el 19.54\% de los votos como diputado por el distrito correspondiente a la comuna de Santiago, pese al adverso escenario generado por la arrasadora victoria de la Nueva Mayoría y su candidata Michelle Bachelet.

La incorporación de Evópoli a esta coyuntura electoral resultó relevante por cuanto visibilizó una estrategia de instalación que, junto al sello de la renovación, incorporaba la complementación con la derecha existente. Lejos de buscar distanciarse de los partidos de la derecha tradicional, optó por actuar como miembro pleno de la coalición e incluso asumir labores de representación y vocería del conglomerado, lo que le permitió adquirir un alto nivel de visibilidad, poco frecuente en organizaciones políticas nuevas.

${ }^{25}$ Evópoli, “La evolución política. Para un Chile más libertario, inclusivo y justo”, 2012, https://www.Evópoli.cl/wp-content/uploads/2016/02/manifiesto.pdf 
Así, en un escenario de profunda crisis del ideario derechista y de avanzada de movimientos sociales impugnatorios, Evópoli emergió como una opción de renovación de un sector político por aquel entonces identificado más con el pasado que con las propuestas de futuro. ${ }^{26} \mathrm{El} \mathrm{mismo} \mathrm{Kast}$ señalaría en este sentido que:

[L]o importante es que podamos mostrar la generación de esta tercera fuerza no como suma cero, sino como una nueva tienda que le pueda dar espacio a gente que quiere tener un nuevo proyecto político: con experiencia de gobierno, liberal y de corte generacional. Aquí habemos personas que no vivimos la dictadura y que sentimos que tenemos algo que decir. ${ }^{27}$

Agenciándose como actor protagónico en la disputa con el gobierno de Bachelet II (2014-2018) y con los actores de la izquierda emergente, su decisión de convertirse en partido político en 2016 constituyó uno de los resultados esperables de esta emergencia.

Ampliamente exitosa en la construcción de un espacio discursivo propio, Evópoli fue ocupando un rol de creciente relevancia en la alianza derechista, participando exitosamente en las primarias presidenciales de 2017 -donde Felipe Kast, candidato del partido, obtuvo el $12.01 \%$ de los votos-, como protagonistas en la campaña y posterior formación del gobierno de Piñera II (2018-2022) y al lograr crear una bancada parlamentaria de seis diputados y dos senadores que le garantizó un lugar clave en "Chile Vamos". En el contexto de la crisis producida desde octubre de 2019, este rol ubicó al partido como articulador clave de la gestión

${ }^{26}$ El vínculo entre Evópoli y el proceso de renovación generacional de la derecha en específico, y del campo político chileno en general, es descrito en Cristóbal Bellolio, Renovación y reemplazo. Por qué es urgente el recambio político en Chile, Santiago, Ariel, 2013.

${ }^{27}$ Felipe Kast, "El talón de Aquiles de la derecha no es su respaldo a Pinochet, sino su falta de diversidad”, La Tercera, 22 de diciembre de 2013. 
gubernamental de Piñera durante la última etapa de su complejo segundo periodo presidencial.

\section{Partido Republicano}

Tal como F. Kast, el fundador y líder del Partido Republicano -José Antonio Kast- cuenta con un estrecho lazo familiar con el núcleo fundante de la UDi pero, a diferencia de su sobrino y fundador de Evópoli, estos lazos fueron acompañados de una extensa trayectoria como militante y dirigente.

Su incorporación a la actividad política se remonta a la década de los ochenta cuando, en su condición de miembro del Movimiento Gremial, ${ }^{28}$ asumió labores de dirigencia en un contexto marcado por el auge de la movilización antidictatorial. Luego, en el contexto posdictatorial, se integró a la UDI, compitiendo exitosamente en una elección en la que alcanzó, con 23\% de los votos, el cargo de Concejal de la comuna de Buin (1996-2000), enclave semiurbano de la periferia de Santiago.

Sus vínculos con el núcleo fundante de la udi le permitieron a J. A. Kast ascender rápidamente en la estructura partidaria al punto que, para las elecciones parlamentarias de 2002, compitió exitosamente por un cupo parlamentario y se ubicó como uno de los liderazgos jóvenes de un partido que, por aquellos años, se encontraba en un auspicioso momento político.

Pese a su emergencia cercana a las cúpulas partidarias, el liderazgo de J. A. Kast se fue posicionando rápidamente como expresión de una generación que comenzaba a reclamar la renovación de los liderazgos y estilos de conducción del partido. Un reclamo que, sin exponer diferencias signi-

${ }^{28}$ El Movimiento Gremial es un movimiento político-universitario de la Universidad Católica con estrechos vínculos con la UDI. Tal como fue el caso de J. A. Kast, un porcentaje importante de sus miembros transitan hacia ese partido una vez producido su egreso de la universidad. 
ficativas a nivel doctrinario, podía entenderse hasta aquel momento como expresión de los procesos de recambio de los liderazgos y estructuras partidarias.

De este modo, si en el caso de F. Kast el impulso renovador generacional se materializaba en un nuevo partido, en el caso de J.A. Kast dicho impulso operaba como parte de un proceso partidario interno. Dos caminos distintos para lo que, hasta entonces, era el mismo objetivo de incorporación de una nueva generación a la política partidaria.

Movido por esta voluntad de representar a una nueva generación militante en las elecciones internas de 2008, J.A. Kast decidió disputar la presidencia del partido a la generación fundacional que, tras más de 20 años, continuaba conduciendo los destinos de la UDI. "Estoy proponiéndoles a muchas personas dentro de la UDI que demos un golpe a la cátedra y nos juguemos por un ideal joven y renovado", ${ }^{29}$ diría el entonces desafiante candidato. Una disputa que en 2010 decide repetir, para ser nuevamente derrotado a manos de uno de los líderes tradicionales del partido, el senador Juan Antonio Coloma.

A partir de entonces, el proceso de distanciamiento partidario de J.A. Kast se acelera. Progresivamente, su perfil renovador se fue modificando, hasta ubicarse finalmente como exponente de una cruzada por la restauración doctrinaria de un partido que, según su diagnóstico, se habría alejado de sus principios. De "joven promesa" a "defensor de los principios", fue cultivando un perfil marcadamente ideológico que le valió crecientes conflictos con su sector.

Distanciándose de los sectores de su partido más próximos al gobierno de Piñera, J.A. Kast se apropiaba de los diagnósticos críticos que se iban gestando dentro de la UDI, representando así el sentir de liderazgos tan importantes como el de uno de sus fundadores, Jovino Novoa, quien

${ }^{29}$ J.A. Kast, "Lanzado mi candidatura a la presidencia de la UDI es hasta el final”, La Segunda, Santiago, 3 de junio de 2008. 
expresaba de esta manera el sentimiento de desafección que primaba por aquel entonces en la militancia gremialista:

Si bien el proceso de desdibujamiento que ha vivido la centroderecha en la última década es responsabilidad de los partidos, la guinda de la torta la puso este gobierno, al abrazar ideas de la Concertación como si fuesen propias y al poner en la agenda temas que no estaban en nuestro programa de gobierno [...] Esta actitud errática tiene una sola causa: la ausencia de un ideario definido". 30

La construcción y apuesta por este perfil doctrinario fue lo que, en definitiva, permite entender el alejamiento de J.A. Kast de la UDI, que se materializó finalmente con su renuncia en mayo de 2016. En su carta de renuncia, la vocación restauradora del futuro líder republicano queda claramente expresada en su crítica a la tendencia del partido por el crecimiento electoral a costa del sacrificio de sus principios e identidad: "No podía permanecer indiferente cuando sentí que la UDi a la que yo entré comenzó a alejarse de su proyecto fundador, de su base fundamental, y que lentamente se transformó en algo muy distinto, dominada por un afán de "ser el partido más grande" a cualquier costo. Y ese costo lo hemos pagado: dejamos de hacer aquello para lo que éramos buenos y que fue lo que nos hizo grandes". ${ }^{31}$

A la renuncia de J.A. Kast se fueron sumando cientos de militantes de la UDI articulados en torno a su liderazgo, y se irían agrupando en un espacio inicialmente inorgánico pero que, crecientemente, iba expresando una voluntad por relevar los aspectos doctrinarios de una derecha tensionada entre su identidad y las obligaciones pragmáticas propias de la

30 Jovino Novoa, Con la fuerza de la libertad. La batalla por las ideas en Chile, Santiago, Antártica, 2013, p. 23.

${ }^{31}$ José Antonio Kast, "Carta de renuncia a la UDI", s/p, https://www.fa cebook.com/notes/jos\%C3\%A9-antonio-kast/carta-de-renuncia-a-laudi/1015064368585389/ 
condición de gobierno, especialmente en un contexto de politización de la desigualdad social.

A inicios de 2017, J. A. Kast anuncia su candidatura presidencial como independiente y se resta del proceso de primarias presidenciales de la coalición "Chile Vamos". De ahí en adelante, su posicionamiento como adalid de los principios de la derecha tradicional, sus críticas a la candidatura de Piñera y su tono marcadamente confrontacional lo ubicaron en un lugar de alta visibilidad política. El camino propio hacia la construcción de una alternativa partidaria había iniciado.

Los resultados de la elección de 2017, en que su candidatura alcanzó casi $8 \%$ de la votación, evidenciaron la existencia de un espacio disponible para esta expresión política. Ello derivó en la decisión de encabezar la constitución primero de un movimiento -Acción Republicana (2018)- y luego de un partido ubicado en un lugar de independencia respecto a la Coalición "Chile Vamos". Un partido cuyo propósito central, como veremos más adelante, es el de recuperar aquellos valores fundacionales amenazados por lo que se identifica como un sistemático avance de "la ideología de izquierda".

En la fundación del Partido Republicano, en definitiva, se conjugan dos elementos: por una parte, la pertenencia privilegiada de su líder al núcleo duro de la derecha tradicional y, por la otra, su ubicación como un espacio impugnador en nombre de, paradójicamente, sus valores fundantes. Estos dos componentes en principio contradictorios son los que caracterizan la identidad de este referente que, más que abrirse hacia nuevos tópicos o promover la incorporación de nuevas generaciones, ha centrado su acción hacia la búsqueda de erigirse como representación de una identidad ideológica supuestamente abandonada por los partidos de la derecha tradicional. ${ }^{32}$

32 Para una discusión respecto a las modalidades de surgimiento de nuevas organizaciones $y$, en específico, de organizaciones fundadas en el 
NARRATIVAS DE ORIGEN Y CONSTRUCGIÓN DE LA IDENTIDAD PARTIDARIA: COMPONENTES DE LA NUEVA DERECHA

Tal y como describimos en el apartado anterior, la formación de Evópoli y el PR constituye una de las tantas consecuencias de la llegada de la derecha al gobierno en un contexto marcado por la emergencia de movimientos sociales que impugnaban el modelo socioeconómico e institucional. Con modalidades y ritmos distintos, ambas organizaciones buscan ocupar un espacio abierto al calor de las dificultades de los partidos tradicionales, los desafíos generados por la intensificación de la movilización social y la apertura de una reflexión en torno a los alcances y límites de la derecha en un contexto de intenso cambio político y social.

Incluso antes de su constitución como partidos políticos formales, Evópoli y PR fueron desplegando un trabajo destinado a su instalación como actores relevantes, la institucionalización de sus estructuras orgánicas y la producción de un discurso distinguible y con suficiente potencia de interpelación. Un trabajo que ha tenido distintos hitos que van desde su constitución como organizaciones, sus posicionamientos frente al gobierno de la Nueva Mayoría, sus políticas de alianza, sus estrategias electorales y sus modos de relación con el gobierno de Piñera II.

Esta identidad diferencial se fue configurando inicialmente a partir de la nominación de un exterior constitutivo compartido, un componente de negatividad asociado con el diagnóstico de una coyuntura de auge del "izquierdismo", crisis de las ideas representadas por la derecha y decadencia del modelo de desarrollo. Pese a la distancia temporal que marca

objetivo de recuperar la identidad perdida de organizaciones ya existentes, véase Allan Sikk, "Newness as a winning formula for new political parties”, Party Politics (2011), pp. 465-486. Para el caso del Partido Republicano y su relación con los partidos tradicionales de la derecha, véase Cristóbal Rovira K, "La (sobre)adaptación programática de la derecha chilena y la irrupción de la derecha populista radical", Colombia internacional (2019), pp. 29-61. 
sus respectivas fundaciones y énfasis doctrinarios, en sus respectivos relatos es posible observar este común denominador, traducido en la necesidad de responder con nuevos bríos a lo que se interpretaba como un contexto sociohistórico adverso respecto al cual las organizaciones tradicionales de la derecha no estarían respondiendo de modo adecuado.

En el caso de Evópoli, sus líderes identifican su nacimiento con la búsqueda de respuestas al clima social y político generado a partir de las movilizaciones sociales de 2011 y su apropiación discursiva por la izquierda. Según su diagnóstico, este ciclo de movilizaciones habría impactado con fuerza, produciendo entre otras consecuencias la izquierdización de la Concertación, coalición que habría optado por distanciarse de su propio legado, liderar una oposición frontal al gobierno de Piñera y promover la creación de un proyecto de transformación radical que derivó en la formación de una nueva coalición política y el retorno al gobierno de Bachelet (2014-2018).

Frente a este escenario adverso, Evópoli emergería con el objetivo de construir una derecha liberal capaz de enfrentar la hegemonía izquierdista. Para ello, una idea fuerza fue la de recuperar la "senda de crecimiento y paz social" abandonada por la centroizquierda, construyendo un referente desprovisto de la mochila autoritaria de la derecha tradicional, sin tópicos vedados y con una total convicción democrática:

No cabe duda que, desde el retorno a la democracia, Chile ha sido extremadamente exitoso en distintos planos [...] Y aunque desde la izquierda se niegue este hecho, al punto de avergonzarse de los éxitos de la Concertación de la que muchos fueron parte y, a partir de ahí, dejarse tentar por lógicas refundacionales, la evidencia es irrebatible. Nosotros reconocemos y reivindicamos con fuerza este progreso, al tiempo que creemos que los indudables desafíos que el país enfrenta deben abordarse buscando grandes acuerdos y construyendo sobre 
lo obrado, en lugar de al alero del espejismo de las lógicas refundacionales. ${ }^{33}$

Un aspecto central en esta relación antagónica con la izquierda fue la decisión de disputarle el sentido de las extendidas demandas en torno a la justicia y la desigualdad social. La consigna "los niños primero", en este sentido, representaba una forma de abordar los problemas de la sociedad chilena con distancia del protagonismo alcanzado por los "grupos de presión", los "intereses particulares" 34 y las formas antagónicas propias de los movimientos universitarios que encabezaron la protesta social desde 2011, colocando el acento más en la "igualdad de oportunidades" que en el énfasis redistributivo propio de la izquierda.

El nacimiento del PR también es narrado por sus fundadores como una reacción necesaria frente al avance de "la izquierda" y los "grupos movilizados". Sus permanentes referencias a la "mayoría silenciosa" y el "sentido común" en oposición a la imposición de una minoría con capacidad de presión establece un origen similar al propuesto por Evópoli: la búsqueda de una respuesta desde la derecha a la irrupción, primero, de movimientos de impugnación y la imposición, luego, de un proyecto de gobierno de tendencias "populistas". Y así lo expresa:

Chile ha perdido la confianza en sus instituciones y la credibilidad de las personas con la política, arrastrándonos a todos en un espiral de desilusión y pesimismo que, inevitablemente, no sólo le pone un freno al desarrollo de nuestro país, sino que nos acerca peligrosamente a los brazos del populismo que, si

33 Felipe Kast, Programa de gobierno del candidato a la presidencia $\mathrm{Fe}$ lipe Kast S. 2018-2022. Principales acciones, iniciativas y proyectos, 2017, https://www.servel.cl/wp-content/uploads/2017/05/ProgramaGobiernoFelipeKast_mayo2017.pdf

34 "Felipe Kast: 'En un acto de genuflexión con la bancada estudiantil el gobierno le quitó piso a Eyzaguirre'”, La Tercera, 24 de julio de 2014. 
bien ha fracasado en todo el mundo, es capaz de seducir a los pueblos y arrastrarlos por un mal camino. ${ }^{35}$

En la configuración de sus respectivas identidades, ambas organizaciones refieren a una exterioridad -el binomio movimiento estudiantil/izquierda- que opera como condición de posibilidad para su germinación. Pero estas coincidencias desaparecen al determinar la forma de enfrentar la izquierdización y el debilitamiento de las ideas de derecha. Mientras para Evópoli el problema está en la falta de diversidad en un sector dominado por el conservadurismo, demasiado atado a su legado autoritario e incapaz de actualizarse para atraer a las nuevas generaciones, para los republicanos las dificultades del sector se originan al haberse "desviado" de las orientaciones y lineamientos que históricamente han dado vida a la derecha.

Estas diferencias derivan, como es lógico suponer, en la búsqueda por construir instrumentos políticos con objetivos diferenciados. Mientras Evópoli buscaba promover la disputa del "centro político", moderando la alianza derechista e incorporando nuevos actores, el PR optaba por reencontrarse con el ethos de una derecha desviada de su ideario. Mientras en unos se trataba de incorporar nuevos rostros, en otros la búsqueda era por reincorporar a los decepcionados:

La Concertación perdió su capital político cuando giró hacia la extrema izquierda y cuando abandonó a la gran mayoría de los chilenos a los que no les gusta ver un Chile polarizado ni dedicado simplemente a las peleas [...] Con la misma convicción, creo que tenemos que cuidar de que Chile Vamos no gire hacia la extrema derecha y no abandonemos lo que se ha

${ }^{35}$ José Antonio Kast, Un programa para volver a creer, Programa elección presidencial 2017, https://www.servel.cl/programas-de-candidatu ras-a-presidente-de-la-republica/ 
venido construyendo gracias también al esfuerzo del Presidente Piñera, de incluir y gobernar para todos los chilenos. ${ }^{36}$

Los chilenos están cansados de propuestas tibias y de proyectos ambiguos que apenas se diferencian. Hay principios y convicciones irrenunciables. ${ }^{37}$

Estas diferencias explican en gran medida las diferentes estrategias de interpelación utilizadas por unos y otros. En el caso de Evópoli, sus llamados se centran en la idea de construir un espacio militante análogo al de los "emprendedores”, cuyas energías están puestas en la materialización de iniciativas concretas. Tanto en su estética como en sus ideas fuerza a sus convocatorias a sumarse al proyecto, la incorporación de "miradas nuevas" y "modernas" constituye un eje central en la estrategia de un partido que, como decíamos antes, se volcó a la tarea de sumar aquel mundo de generaciones independientes, distanciado de la derecha tradicional.

El PR, por su parte, buscó en la "decadencia” de los partidos tradicionales su principal motivación y fuente de atracción. En su relato originario, el llamado principal es a la militancia que ha ido abandonando los partidos tradicionales y que busca un nuevo espacio para la defensa y expresión de sus principios. ${ }^{38}$ En consecuencia, el factor generacional

36 "Felipe Kast: "veo con preocupación a miembros de Chile Vamos tentados a girar a la extrema derecha'”, La Tercera, 15 de diciembre de 2018,

37 José Antonio Kast, "2019”, El Líbero, 1 de enero de 2019.

${ }^{38}$ La primera Mesa Directiva del PR, integrada por 10 dirigentes, contaba entre sus miembros con seis exmilitantes de la UDI, lo que contrastaba con la primera directiva Evópoli, en la que sólo participaban dirigentes sin experiencia militante. No resulta extraño, en este sentido, que pese a la distancia de más de tres décadas que las separa, la declaración de principios del PR contenga extractos idénticos al de la declaración de principios de la UDI. Véase Partido Republicano, "Declaración de principios", https:/ / www.24horas.cl/incoming/article3372081.ece/BINARY/ESTA TUTOS\% 20DEFINITIVOS \% 20PARTIDO \% 20REPUBLICANO \% 20VF\% 2007-062019.pdf y UDI, "Declaración de principios", http:/ / www.udi santiago.cl/ documentos/dec_princip.pdf 
ocupa acá un lugar secundario respecto a la centralidad de su interpelación: el llamado a los militantes que con el correr del tiempo se han "decepcionado", han sido "silenciados" o, directamente, se han ido quedando sin referentes.

\section{Cuadro 1 \\ Narrativas del origen}

\begin{tabular}{|c|c|c|}
\hline Dimensión & Evópoli & Partido Republicano \\
\hline Inspiración & $\begin{array}{l}\text { "Evópoli nace en 2012, en el contexto } \\
\text { [...] de las movilizaciones estudianti- } \\
\text { les, como una respuesta generacional } \\
\text { a un giro hacia la izquierda que esta- } \\
\text { ba tomando la política nacional; y un } \\
\text { grupo de independientes quisimos } \\
\text { levantar un proyecto político para } \\
\text { ofrecerle a Chile una propuesta inte- } \\
\text { gralmente liberal". }{ }^{\text {a }}\end{array}$ & $\begin{array}{l}\text { "Queremos levantar la defensa de } \\
\text { causas, principios y valores, y ha- } \\
\text { cerlo con convicción. Los partidos } \\
\text { son importantes, pero se han des- } \\
\text { vinculado de la realidad". b }\end{array}$ \\
\hline $\begin{array}{l}\text { Diagnósticos } \\
\text { sobre la } \\
\text { derecha } \\
\text { tradicional }\end{array}$ & $\begin{array}{l}\text { "Debiera alegrarnos que hoy día Chi- } \\
\text { le Vamos no es igual que la antigua } \\
\text { Alianza por Chile, donde estaban los } \\
\text { dos partidos conservadores". }{ }^{c}\end{array}$ & $\begin{array}{l}\text { "(la UDI) lentamente se transfor- } \\
\text { mó en algo muy distinto, domina- } \\
\text { da por un afán de "ser el partido } \\
\text { más grande" a cualquier costo. Y } \\
\text { ese costo lo hemos pagado: deja- } \\
\text { mos de hacer aquello para lo que } \\
\text { éramos buenos y que fue lo que } \\
\text { nos hizo grandes". }{ }^{\text {d }}\end{array}$ \\
\hline $\begin{array}{l}\text { Motivaciones } \\
\text { militantes }\end{array}$ & $\begin{array}{l}\text { "Yo dejé mis emprendimientos para } \\
\text { construir una derecha distinta, más } \\
\text { inclusiva, más tolerante, más mo- } \\
\text { derna". e }\end{array}$ & $\begin{array}{l}\text { "No podía permanecer indiferen- } \\
\text { te cuando sentí que la UDI a la que } \\
\text { yo entré comenzó a alejarse de su } \\
\text { proyecto fundador, de su base fun- } \\
\text { damental". }\end{array}$ \\
\hline
\end{tabular}

${ }^{\text {a }}$ La Tercera, 15 de diciembre de 2018, art. cit.

b "José Antonio Kast: 'Este es un gobierno al que le falta carácter, y cuando a uno le pasa eso, cae en la ambigüedad"”, La Tercera, 12 de octubre de 2018.

c "Felipe Kast, senador de Evópoli: 'La ciudadanía quiere ver a un Presidente que tome posición en temas tan importantes como identidad de género", La Tercera, 1 de abril de 2018.

d José Antonio Kast, Carta..., art. cit.

e "Francisco Undurraga, diputado Evópoli: "La diversidad de Chile Vamos no va a permitir asonadas populistas”, La Tercera, 22 de octubre de 2018.

f José Antonio Kast, Carta..., art. cit. 


\section{CuAdRo 1 (conclusión)}

Narrativas del origen

\begin{tabular}{|c|c|c|}
\hline $\begin{array}{l}\text { Receptores } \\
\text { del mensaje } \\
\text { partidario }\end{array}$ & $\begin{array}{l}\text { "Nacimos con dos banderas súper cla- } \\
\text { ras, que era oxigenar la política para } \\
\text { invitar a un mundo que no se sentía } \\
\text { identificado por los partidos de la } \\
\text { derecha tradicional, para que vieran } \\
\text { que existía una nueva opción".g }\end{array}$ & $\begin{array}{l}\text { "Somos la voz de esa mayoría si- } \\
\text { lenciosa, que muchas veces es } \\
\text { acallada por grupos ideológicos. } \\
\text { Queremos movilizar a millones } \\
\text { de chilenos y decirles que confíen } \\
\text { en sus principios, que trabajen en } \\
\text { conjunto y que luchen día a día } \\
\text { por los sueños de sus familias". }\end{array}$ \\
\hline
\end{tabular}

g "Evópoli viene a contribuir a darle continuidad a la centroderecha", $E l$ Día, 9 de julio de 2019.

h Acción Republicana, ¿Quiénes somos?, https://www.accionrepublicana. $\mathrm{cl} /$ quienes-somos/

Estos agenciamientos diferenciales se fueron sedimentando, pasando a formar parte de las identidades de ambos partidos. Mientras Evópoli fue gestando su perfil en torno al encadenamiento metonímico entre los significantes "juventud", "innovación", "renovación" y "liberalismo", en el caso del $\mathrm{PR}$, su ethos partidario se configuró en torno al protagonismo de significantes tales como "principios", "convicciones" y "derecha verdadera".

Tales perfilamientos redundan en una diferenciación central entre ambos partidos: mientras Evópoli configura su identidad con base en la expectativa de "renovar y "refrescar" a la derecha, el PR sostiene su razón de ser en la voluntad por recobrar una identidad perdida a través de los años. Es decir, mientras en el primer caso el aspecto característico de la identidad partidaria es el de una renovación que permite atraer nuevas voluntades a la actividad política, en el segundo es el de una energía restauradora que persigue evitar la desafección de ciudadanos y ciudadanas otrora identificados con una derecha que habría estado perdiendo su identidad.

Por lo mismo, no es extraño que la coyuntura presidencial de 2017 fuera abordada de modos distintos: mientras José Antonio Kast (quien aún no había fundado el PR) decidía competir como candidato presidencial por fuera de la coali- 
ción oficialista, Evópoli (partido que ya se encontraba constituido formalmente) participó de las primarias presidenciales del bloque en las que finalmente triunfó Sebastián Piñera. Estrategias distintas, consecuentes con objetivos claramente distinguibles: mientras por un lado se trataba de producir una diferencia específica en un marco de unidad con los partidos tradicionales, en el caso de J.A. Kast se trataba de producir una frontera diferenciadora con dichos partidos, con miras a la posterior creación de un partido que emergía de la desafección capitalizada de dicha elección.

El desarrollo de las campañas presidenciales permitió observar de forma prístina las estrategias de posicionamiento de ambos liderazgos. Más allá de las múltiples coincidencias programáticas en temas tales como el crecimiento económico, la seguridad pública y el antiestatismo, el despliegue de ambas candidaturas permitió observar profundas diferencias en cuanto a ejes programáticos privilegiados, énfasis, diagnósticos y tonos.

Consideradas desde la dimensión pragmática, la mayor parte de las propuestas de J.A. Kast fueron presentadas de forma intensamente antagónica. El constante establecimiento de fronteras entre quienes apoyan la "paz social" representan el "sentido común" o buscan "lo mejor para Chile", versus quienes promueven el "caos" y el "ideologismo", constituye un elemento muy presente. En ese sentido, sus propuestas programáticas se presentan como una búsqueda de revertir el "daño" infringido a la sociedad por 'la izquierda'", lo que se traduce en la expandida frecuencia de palabras tales como "derogar", "eliminar" o "revertir", que suelen estar presentes en el abordaje programático en las áreas de educación, derechos sexuales y reproductivos y sistema tributario. ${ }^{39}$

Al contrario, las propuestas programáticas de Evópoli se plantearon en forma de "mejoras" más que de ruptura o restauración. Gran parte de éstas se anunciaban con la intención de disolver la oposición binaria entre conservadu-

${ }^{39}$ José Antonio Kast, Un programa .., op. cit. 
rismo-liberalismo, por un lado, o entre ortodoxia neoliberal e igualitarismo, por el otro. Operaba, en este recurso, la búsqueda para indicar la continuidad de un curso de acción "sin" renunciar a otro. Ello, complementado con críticas a una izquierda que se habría desviado del rumbo ejemplar iniciado desde el retorno a la democracia por la misma centroizquierda: "No venimos a borrar con el codo lo que se escribió con la mano. Hay que profundizar y mejorar las reformas, las reformas no son estáticas, e incluso hay consenso en que la reforma educacional no quedó bien hecha”. ${ }^{40}$

Estas diferencias discursivas se encuentran asociadas a lecturas divergentes respecto al pasado reciente. Si bien ambos coinciden, como ya hemos señalado, en la consideración del periodo 2011-2017 como una etapa compleja para el país, en el caso de Evópoli existe una lectura de la historia reciente como un periodo sumamente exitoso al que la centroizquierda aportó sustantivamente. Contrario a ello, la propuesta de J.A. Kast va acompañada de un diagnóstico de dicho periodo como una larga etapa de decadencia caracterizada por la distorsión de las bases del modelo económico-social fundado en dictadura.

Hay un relato. Es el relato de los acuerdos, de gobernar para todos los chilenos. El relato es, de alguna manera, la herencia de lo que fue la Concertación. Es la posibilidad de darles un espacio político a muchos chilenos a través de reformas que los beneficien a todos. ${ }^{41}$

¿Qué hizo la Concertación durante 20 años? Administrar un modelo. No fue una coalición creativa ni impuso avances político-institucionales concretos. Al contrario, fueron las innovaciones de la Concertación las que hicieron mucho daño al diseño original del modelo. ${ }^{42}$

40 "Francisco Undurraga: 'Evópoli no va a vetar a nadie para llegar a acuerdos'”, La Tercera, 31 de diciembre de 2017.

41 "Hernán Larraín Matte, presidente de Evópoli: 'José Antonio Kast todavía es una noticia en desarrollo'”, La Tercera, 27 de abril de 2019.

42 "Columna de José Antonio Kast: ¿Adiós carnaval? ¿Adiós general?”, The Clinic, 18 de febrero de 2018. 
En cuanto a propuestas programáticas propiamente como tales, destacó en J.A. Kast su tendencia al relevamiento de problemáticas sentidas de forma especial por el electorado clásico de la derecha chilena. Es así como, por ejemplo, en el tema de seguridad se incorporó con especial intensidad el tratamiento del así llamado "conflicto chileno-mapuche" desde la perspectiva del combate al terrorismo.

Cuestión similar ocurrió con el tema migratorio. Aunque menos protagónico que el de los populismos de derecha europeos, ${ }^{43} \mathrm{~J}$.A. Kast hizo frecuentes referencias a la necesidad de establecer barreras de ingreso y mecanismos de control que volvieran eficaz la vigencia de la soberanía jurisdiccional del Estado chileno sobre su territorio. Junto a ello, manifestó una constante mención a las Fuerzas Armadas, a la necesidad de fortalecer su presupuesto y avanzar hacia lo que se denomina "trato igualitario ante la ley" para los uniformados implicados en violaciones a los derechos humanos durante la dictadura, tema este último muy sentido por los -minoritarios- segmentos ciudadanos identificados con la dictadura.

En la agenda programática de Evópoli las propuestas vinculadas al combate de la desigualdad social ocuparon un lugar privilegiado. Una porción importante de sus propuestas refiere a mecanismos alternativos al "igualitarismo de izquierda”, en una lógica en la que se pretende articular el liberal-individualismo con la generación de mecanismos que permitan garantizar la "igualdad de oportunidades" y corregir algunas desigualdades producidas por los lugares diferenciales de las personas en la estructura social.

Este foco en la desigualdad es clave en la construcción de un relato diferenciador respecto a la derecha tradicional que, por lo general, tendía a enfrentarse al igualitarismo ya fuera negando la existencia o subvalorando la relevancia de las desigualdades sociales. ${ }^{44}$ Por lo demás, da cuenta de la apuesta

${ }^{43}$ C. Rovira, op. cit.

${ }^{44}$ Para una ilustración de la posición neoliberal ortodoxa respecto a la crisis de 2011 y el problema de la desigualdad, véase Luis Larraín, op. cit. 
por articular renovación generacional con reactualización ideológica. Un discurso en el que, en definitiva, "el mensaje de renovación política se articula de forma no excluyente con un esfuerzo de aggiornamiento ideológico del sector". ${ }^{45}$

Expresión clara de esta voluntad de disputa lo constituye el protagonismo que ocupó en la agenda programática de Evópoli el tema de la infancia que, sintetizada en la fórmula "los niños primero en la fila", ${ }^{46}$ opera como idea fuerza de un abordaje alternativo, despolitizado y tecnificado del problema de la desigualdad social.

Lejos de ser casual, la centralidad del tema infancia operaba como dispositivo crítico frente a la política de reformas educativas promovidas por el gobierno de Bachelet, especialmente frente al aumento del gasto público generado por la gratuidad universitaria. En oposición a esto, el programa de Evópoli proponía reorientar y focalizar el gasto en educación hacia la primera infancia y el sistema escolar, disputando la centralidad que en ese entonces había adquirido el debate sobre educación superior, en el cual el movimiento social estudiantil ocupaba un rol de suma relevancia.

Otro elemento articulado con la agenda infancia fue la adopción homoparental, propuesta que en este caso operaba como eje de diferenciación con los sectores conservadores de la derecha. A diferencia del encuadre tradicional que asume este tipo de políticas como parte de una agenda vinculada a la "libertad individual", en el caso de Evópoli el énfasis se coloca en el "bien superior del niño", morigerando de cierta forma el efecto potencialmente negativo de la incorporación de una propuesta más bien ajena al electorado de derecha, pero marcando una diferencia con las voces más conservadoras del sector. ${ }^{47}$ p. 159 .

${ }^{45}$ Stéphanie Alenda, Carmen le Foulon y Sebastián del Hoyo, op. cit.,

46 "Evópoli: 'Afortunadamente el ministro Eyzaguirre nos escuchó", La Tercera, 14 de mayo de 2014.

${ }^{47}$ Cristóbal Rovira, 2019, op. cit.; Stéphanie Alenda, Carmen le Foulon y Sebastián del Hoyo, op. cit. 
De modo contrario, J.A. Kast optó por reivindicar una posición conservadora ortodoxa de oposición a la agenda de valores continuada "irresponsablemente", según su juicio, por la administración Piñera. Materias como la adopción homoparental, el aborto regulado o el matrimonio entre personas del mismo sexo constituirían, en este sentido, parte de una agenda exterior y opuesta al ideario de derecha, pero asumida como propia en vista a una "errada" voluntad de aproximación al centro político, necesaria de ser corregida.

\begin{tabular}{|c|c|c|}
\hline & \multicolumn{2}{|c|}{ PROGRAMAS PRESIDENCIALES ${ }^{\mathrm{a}}$} \\
\hline Materia & $\begin{array}{c}\text { Primera vuelta presidencial } \\
\text { José Antonio Kast (independiente) }\end{array}$ & $\begin{array}{l}\text { Primarias presidenciales Chile } \\
\text { Vamos Felipe Kast (Evópoli) }\end{array}$ \\
\hline Seguridad & $\begin{array}{l}\text { "La mayor amenaza para la de- } \\
\text { mocracia y la convivencia pací- } \\
\text { fica entre los chilenos radica en } \\
\text { la incontrolable expansión del } \\
\text { narcotráfico }[. . .] \text { todo lo cual se } \\
\text { ve agravado por sus conexiones y } \\
\text { redes con el terrorismo ideológico } \\
\text { de movimientos que creen en la } \\
\text { agitación social y en la violencia } \\
\text { como un medio legítimo para al- } \\
\text { canzar el poder". }\end{array}$ & $\begin{array}{l}\text { "No podemos pretender borrar } \\
\text { de la noche a la mañana la delin- } \\
\text { cuencia. No hay propuestas mági- } \\
\text { cas ni soluciones únicas. Creemos } \\
\text { que para abordar este desafío te- } \\
\text { nemos que mirar la película com- } \\
\text { pleta más que una foto. Bajar los } \\
\text { niveles de delincuencia y poder } \\
\text { vivir más tranquilos requiere en- } \\
\text { tender que nos enfrentamos a un } \\
\text { proceso de largo plazo, en el que } \\
\text { ninguna medida por sí sola será } \\
\text { suficiente". }\end{array}$ \\
\hline Migración & $\begin{array}{l}\text { "En materia de inmigración vamos } \\
\text { a exigir el cumplimiento de la ley } \\
\text { vigente y reforzar los controles y } \\
\text { las herramientas que tiene el Es- } \\
\text { tado para aplicar efectivamente } \\
\text { la ley". }\end{array}$ & $\begin{array}{l}\text { "Necesitamos de una ley moder- } \\
\text { na, que genere los incentivos para } \\
\text { un proceso migratorio ordenado, } \\
\text { permitiendo un mejor registro } \\
\text { y control [...] Que sea clara en } \\
\text { precisar los derechos y deberes de } \\
\text { los inmigrantes [...] y que defina } \\
\text { una institucionalidad migratoria } \\
\text { robusta". }\end{array}$ \\
\hline
\end{tabular}

a Todas las referencias expuestas corresponden a los programas de los candidatos presidenciales, que pueden ser revisados en José Antonio Kast, op. cit. y Felipe Kast, op. cit. 


\begin{tabular}{|c|c|c|}
\hline $\begin{array}{l}\text { Modernización } \\
\text { del Estado }\end{array}$ & $\begin{array}{l}\text { "Los gastos por operadores po- } \\
\text { líticos y apitutados equivalen a } \\
\text { US\$ } 800 \text { millones, también hemos } \\
\text { visto el Transantiago que son } \\
\text { otros US\$ } 800 \text { millones y así va- } \\
\text { mos a ir encontrando dentro de lo } \\
\text { que son las reparticiones del Esta- } \\
\text { do el malgasto público". }\end{array}$ & $\begin{array}{l}\text { "Reformar el Estado significa de- } \\
\text { volverlo a los ciudadanos, que no } \\
\text { sea una agencia de empleo para pa- } \\
\text { gar favores políticos, que no haya } \\
\text { operadores políticos sino servido- } \\
\text { res públicos de excelencia. Signifi- } \\
\text { ca profesionalizar completamente } \\
\text { la labor estatal". }\end{array}$ \\
\hline Agenda valórica & $\begin{array}{l}\text { "Revertir de manera inmediata, la } \\
\text { Ley de Aborto que promueve Mi- } \\
\text { chelle Bachelet, enviando un pro- } \\
\text { yecto para lograr su derogación. } \\
\text { Junto con ello, presentar una } \\
\text { agenda de soporte permanente } \\
\text { y aprobar los recursos necesarios } \\
\text { para apoyar a las madres y fami- } \\
\text { lias que tienen que llevar adelante } \\
\text { embarazos no deseados o comple- } \\
\text { jos, y revisar los mecanismos y pro- } \\
\text { tocolos de adopción". }\end{array}$ & $\begin{array}{l}\text { "Creemos que, al alero del reco- } \\
\text { nocimiento que todas las personas } \\
\text { nacen libres e iguales en dignidad } \\
\text { y derechos, el matrimonio civil } \\
\text { debe estar abierto a todos, inclu- } \\
\text { yendo a las parejas del mismo sexo } \\
\text { que hoy el Estado excluye de este } \\
\text { contrato civil. Por la misma razón, } \\
\text { la ampliación de la elegibilidad } \\
\text { y acceso a este contrato va de la } \\
\text { mano de todas las implicancias le- } \\
\text { gales y simbólicas que éste tiene, } \\
\text { incluyendo la posibilidad de adop- } \\
\text { ción de hijos". }\end{array}$ \\
\hline
\end{tabular}

a Todas las referencias expuestas corresponden a los programas de los candidatos presidenciales, que pueden ser revisados en José Antonio Kast, op. cit. y Felipe Kast, op. cit.

Estas posiciones programáticas emergidas de la coyuntura electoral de 2017 fueron consolidándose como marcas distintivas tanto de Evópoli como del PR, y constituyeron un insumo relevante para la producción de sus identidades. Mientras Evópoli optó por consolidar su lugar diferencial en el espacio de la derecha tradicional, instalando nuevos temas en la agenda y colocando la renovación generacional como eje identitario, J. A. Kast generó, a partir de dicha coyuntura, las condiciones para la creación del Partido Republicano, organización cuyo núcleo discursivo se constituyó precisamente con base en la voluntad para restaurar los valores y principios de la derecha tradicional supuestamente extraviados al calor de la disputa con un progresismo al alza. 


\section{Conclusiones}

En este artículo hemos querido aproximarnos a los procesos de creación de Evolución Política (Evópoli) y Partido Republicano (PR), dos organizaciones que han pasado a formar parte de la nueva configuración de la derecha política chilena. A partir de una reconstrucción sociohistórica de las dinámicas que condujeron a su formación, nos propusimos relevar sus respectivos ejes discursivos, su identidad partidaria y la plataforma programática que las define, buscando de este modo extraer algunas pistas sobre el rol que tendrán en el complejo periodo abierto a partir de los hechos del 18 de octubre de 2019 y del proceso constituyente actualmente en curso.

Mientras en un caso -Evópoli- pudimos observar el desarrollo de una estrategia de renovación generacional que busca complementar el espacio de la derecha tradicional, en el otro-PR- observamos cómo la restauración de valores abandonados se constituye en el eje sobre el cual adquiere sentido la movilización de una estrategia de construcción partidaria que antagoniza directamente con la derecha tradicional. En ambos casos, la intención era producir un lugar distintivo y capaz de interpretar de modo adecuado los sentires y demandas de una sociedad cada vez más compleja y heterogénea, y de un sector político sometido a fuertes desafíos desde su retorno al gobierno en 2010, en especial por la creciente irrupción de movimientos sociales contenciosos en la esfera pública.

Ahora bien, la deriva de estas organizaciones -al igual como del conjunto de actores políticos chilenos- se vio sumamente alterada como resultado de los eventos que, a partir del 18 de octubre de 2019, dieron inicio a la mayor crisis social y política desde el retorno de Chile a la democracia en 1990.

Activado a poco más de un año del retorno de la derecha al gobierno en 2018, el ciclo abierto el 18 de octubre de 2019, y que actualmente ha derivado en un inédito proceso constituyente, encontraba a Evópoli y al PR en dos lugares muy distintos: mientras los primeros, en su condición de in- 
tegrantes de la coalición gubernamental, ocupaban carteras ministeriales cada vez más relevantes, ${ }^{48}$ los segundos se ubicaban en una posición fluctuante entre la distancia crítica y la oposición frontal. Desde lugares diferentes, enfrentaron lo que sin dudas ha constituido el mayor desafío para la derecha chilena en décadas: superar el profundo desgaste hegemónico del proyecto histórico con el cual este sector político se ha identificado desde su implementación en el contexto de la dictadura militar iniciada en 1973. Un desafío que, sin dudas, trascendió a estos partidos y se extendió en todo el espectro partidario e intelectual de la derecha chilena. ${ }^{49}$

Así, mientras Evópoli -desde el gobierno y sus liderazgos parlamentarios- desempeñó un papel central en la generación del acuerdo político que abrió paso al proceso constituyente actualmente en curso, el PR optó por oponerse enérgicamente y erigirse como defensor de la institucionalidad representada en la Constitución de 1980. Estas diferencias, expresadas de modo transversal en los partidos tradicionales de la derecha, ubicaron a las dos nuevas organizaciones en una posición de fuerte tensión de cara al inicio del proceso de cambio constitucional.

Sin embargo, con el avance del proceso constituyente se produjeron puntos de encuentro táctico. El primero de ellos se dio como resultado del significativo número de dirigentes y militantes de Evópoli que se pronunciaron, al igual que

${ }^{48} \mathrm{Al}$ inicio del gobierno de Piñera en 2018, Evópoli ocupó dos carteras ministeriales, las que se vieron incrementadas durante el periodo más álgido de la crisis, al punto de llegar a ocupar dos de los ministerios más importantes: Interior (Gonzalo Blumel) y Hacienda (Ignacio Briones).

${ }^{49}$ Como respuesta a la crisis de octubre de 2019, diversos sectores de la derecha han protagonizado un extenso debate, aún en curso, en torno a su rol en la crisis y sus horizontes posibles. Algunos de los aspectos claves de este debate pueden verse expuestos en Hugo Herrera, "Dos derechas", en La Tercera, 24 de junio de 2020; Sebastián Rumie, Stephanie Alenda y Joaquín Fernández, "Transformaciones y continuidades: las sensibilidades de la derecha chilena", en CIPER, 15 de agosto de 2020; Felipe Schwember, "Peronismo Chileno", en La Segunda, 3 de junio de 2020. 
todo el PR, por la opción de "rechazo" para el plebiscito en que se consultaba a la ciudadanía sobre su acuerdo respecto al inicio del proceso constituyente. ${ }^{50} \mathrm{Y}$ el segundo, en la decisión del conjunto de partidos de la derecha chilena -incluidos Evópoli y el PR- de presentar una lista conjunta para las elecciones de convencionales constituyentes realizada el 15 y 16 de mayo de 2021, ${ }^{51}$ donde la coalición obtuvo sólo $24 \%$ del total de escaños con que se formó la Convención Constitucional que entró en funciones el 4 de julio.

Es así como, en un escenario de fuerte dislocación y crisis de la derecha política en su conjunto, Evópoli y el PR buscan producir un lugar de distinción que les permita ubicarse como actores relevantes en el ciclo abierto en 2019. Cuál de los dos actores logrará mayor éxito es una cuestión aún por verse, pero es posible observar algunas tendencias.

Si lo observamos desde un punto de vista electoral, los resultados de las recientes megaelecciones de mayo de 2021 permiten anticipar una mayor fortaleza de Evópoli, tanto en votación como en elegibilidad y presencia en los órganos de representación. De hecho, mientras Evópoli obtuvo el $4.4 \%$ de la votación y un total de cinco convencionales, el PR obtuvo poco más de $1 \%$ y ningún constituyente; en el caso de las elecciones de alcaldes, si bien ambos partidos obtuvieron un porcentaje cercano al 1\% de los votos, Evópoli logró triunfar en Vitacura, emblemático bastión de la derecha y la comuna con mayores ingresos del país; por último, en las elecciones para la creación de los concejos municipales, considerada como el indicador más aproximado al peso real de los partidos políticos chilenos, Evópoli obtuvo $4.8 \%$ y el PR $3.1 \%$.

${ }^{50}$ En dicho plebiscito, realizado el 25 de octubre de 2020 en medio de la crisis sanitaria provocada por la pandemia de CoviD-19, la ciudadanía se pronunció a favor del proceso constituyente en un porcentaje superior a $78 \%$.

51 Debido a la emergencia sanitaria y fruto de varias postergaciones, las elecciones del 15 y 16 de mayo fundieron cuatro elecciones en una sola jornada: convención constitucional, gobernadores regionales, alcaldes y concejales. 
El conjunto de estos resultados, situados en un contexto electoralmente muy adverso para la derecha chilena, permiten anticipar una presencia acotada pero significativa de Evópoli en el ciclo político que inicia, cuestión que en principio contrasta con la escasa presencia del PR en los espacios de representación local y constituyente. Sin embargo, y pese a esto, el PR tiene un conjunto de atributos que permiten anticipar que seguirá siendo un actor político incidente. Y ello al menos por dos factores que, a nuestro juicio, le permitirán tener un rol en el proceso político: en primer lugar, por la maciza presencia en el debate público de su líder y fundador J. A. Kast, quien concurrirá por segunda vez como candidato a las elecciones presidenciales de noviembre de 2021, compitiendo con el independiente liberal Sebastián Sichel, candidato emergido de las elecciones primarias de la coalición derechista en las que Evópoli obtuvo menos de $10 \%$ de las preferencias de dicho sector; en segundo lugar, por el claro agenciamiento del PR en el lugar de la restauración y la crítica a las formas "concesivas" y "blandas" de la derecha política, agenciamiento que, si bien puede no ser mayoritario, se expresa en un discurso claro y distintivo que contrasta con la mayor ambigüedad y diversidad de posiciones con las que Evópoli ha enfrentado la reciente crisis política.

En definitiva, cuál será específicamente el rol de Evópoli y el PR, y cuál su nivel de éxito, son preguntas que aún no pueden ser respondidas de manera definitiva, pero lo cierto es que, en el escenario de la fuerte dislocación que caracteriza al proceso político chileno actual, ambos partidos tendrán un lugar e incidencia en la creación de la nueva derecha que deberá encarar el proceso constituyente recientemente abierto y cuya deriva final aún está sometida a la naturaleza contingente de la política. 


\section{REFERENCIAS}

\section{Bibliografia}

Abal Medina, Juan, "El surgimiento de los partidos políticos, una propuesta interpretativa”, en Juan Abal Medina (comp.), Los senderos de la nueva izquierda partidaria, Buenos Aires, Prometeo, 2006.

Alenda, Stéphanie, Andrea Gartenlaub y Karin Fischer, "Ganar la batalla de las ideas: el rol de los think tanks en la configuración de la nueva centro-derecha chilena", en Stéphanie Alenda (ed.), Anatomía de la derecha chilena: Estado, mercado y valores en tiempos de cambio, Santiago, Fondo de Cultura Económica, 2020, pp. 119-156.

Alenda, Stéphanie, Carmen le Foulon y Sebastian del Hoyo, "Evolución política y la renovación liberal en Chile", en Stéphanie Alenda (ed.), Anatomía de la derecha chilena: Estado, mercado y valores en tiempos de cambio, Santiago, Fondo de Cultura Económica, 2020, pp. 157-190.

Avendaño, Octavio, "Fracturas y representación política en el movimiento estudiantil: Chile 2011”, Última década, núm. 41, (2014), pp. 41-68.

Bellolio, Cristóbal, Renovación y reemplazo. Por qué es urgente el recambio político en Chile, Santiago, Ariel, 2013.

Bоввіо, Norberto, Derecha e izquierda. Razones y significados de una distinción política, Madrid, Taurus, 1996.

Bourdieu, Pierre, "Algunas propiedades de los campos", en Campo de poder, campo intelectual, Buenos Aires, Montressor, 2003, pp. 9-50.

Collier, Ruth y David Collier, Shaping the political arena: Critical junctures, the labor movement, and regime dynamics in Latin America, Notre Dame, University of Notre Dame Press.

DÁvila, Mireya "Tecnocracia y democracia en el Chile contemporáneo: el caso de los gobiernos de la Concertación (1990-2010)", Revista de Sociología, 24, (2010), pp. 199-217.

Durán, Carlos, "El acontecimiento estudiantil y el viraje del proceso sociopolítico chileno", Observatorio social de América Latina, XIII (31), 2012. 
DurÁn, Carlos, "Chile vuelve al vecindario: de la complacencia al malestar”, en Álex Caldera y Armando Chaguaceda (coords.), Democracia en América Latina: entre el ideal utópico y las realidades políticas, México D.F., Fontamara, 2016, pp. 187-209.

DurÁn, Carlos, "Campo político-institucional y procesamiento del malestar social en Chile, 1999-2009”, Izquierdas, núm. 40, 2018, pp. 1-32.

FERnÁNDEZ, Joaquín y Sebastián Rumié, "Las transformaciones de la derecha chilena: desafíos, adaptaciones y renovaciones (19322010)", en Stéphanie Alenda (ed.), Anatomía de la derecha chilena. Estado, mercado y valores en tiempos de cambio, Santiago, FCE, 2020, pp. 43-86.

FigueroA, Francisco, Llegamos para quedarnos. Crónicas de la revuelta estudiantil, Santiago, LOM, 2013.

Funk, Robert, "El relato político en el primer año del gobierno de Piñera Política”, Revista de Ciencia Política, vol. 49, núm. 2, 2011, p. 151-159.

Gartenlaub, Andrea, Trayectorias, permanencias y continuidades de la competencia política y de los perfiles ideológicos de los partidos de derecha chilenos en la posdictadura, tesis para optar al grado académico de doctora en Ciencias Sociales, Santiago, Universidad de Chile, 2018.

Herrera, Hugo, La derecha en la crisis del bicentenario, Santiago, Ediciones UDP, 2014.

LaClaU, Ernesto, La razón populista, Buenos Aires, FCE, 2005.

LARRAín, Luis, El regreso del modelo, Santiago, Libertad y Desarrollo, 2012.

Levistky, Steven y Kenneth M. Roberts (eds.), The Resurgence of the Latin American Left, Baltimore, The Johns Hopkins University Press, 2011.

Luna, Juan Pablo y Cristóbal Rovira (eds.), The resilience of the Latin American Right, Baltimore, The Johns Hopkins University Press, 2014.

Mainwaring, Scott y Mariano Torcal, "La institucionalización de los sistemas de partidos y la teoría del sistema partidista después de la tercera ola democratizadora”, América Latina Hoy, 41, 2005, pp. 141-173. 
Mansuy, Daniel, Nos fuimos quedando en silencio. La agonía del Chile de la transición, Santiago, Instituto de Estudios de la Sociedad, 2016. Mayorga, Rene Antonio, "Antipolítica y Neopopulismo en América Latina”, Relaciones, 161, Serie Convivencias (xv), Montevideo, Periódica S.R.L, 1998.

Muñoz TAmayo, Víctor, Historia de la UDI. Generaciones y cultura política (1973-2013), Santiago, Ediciones Universidad Alberto Hurtado, 2016.

NovoA, Jovino, Con la fuerza de la libertad. La batalla por las ideas en Chile, Santiago, Antártica, 2013.

Rovira K., Cristóbal, "La (sobre)adaptación programática de la derecha chilena y la irrupción de la derecha populista radical", Colombia internacional, 2019, pp. 29-61.

SıкK, Allan, "Newness as a winning formula for new political parties", Party Politics, 2011, pp. 465-486.

Stossel, Soledad, "Giro a la izquierda en la América Latina del siglo xxi: revisitando los debates académicos”, Polis, vol. 13, núm. 39, (2014), pp. 123-149.

Svampa, Maristella, "Posprogresismos, polarización y democracia en Argentina y Brasil”, Nueva Sociedad, 284, 2019, pp. 121-134.

VAras, Augusto, El gobierno de Piñera (2010-2014), Santiago, Catalonia, 2013.

VILAs, Carlos, “¿Populismos reciclados o neoliberalismo a secas? El mito del neopopulismo latinoamericano", Revista Venezolana de Economía y Ciencias Sociales, vol. 9, núm. 3, septiembre-diciembre de 2003, pp. 13-36.

Vommaro, Gabriel, "Propuesta republicana y sus mundos de pertenencia: una perspectiva sociocultural de la nueva centro-derecha argentina”, en Alenda, Stéphanie (ed.), Anatomía de la derech a chilena: Estado, mercado y valores en tiempos de cambio, Santiago, FCE, 2020, pp. 301-322.

Fuentes primarias y periódicas

Acción Republicana, ¿Quiénes somos?, disponible en: https://www. accionrepublicana.cl/quienes-somos/ 
"Evópoli: 'Afortunadamente el ministro Eyzaguirre nos escuchó"”, La Tercera, 14 de mayo de 2014.

Evópoli, "La Evolución política. Para un Chile más libertario, inclusivo y justo”, 2012, https://www.Evópoli.cl/wp-content/uploads/ 2016/02/manifiesto.pdf

"Evópoli viene a contribuir a darle continuidad a la centroderecha”, El Día, 9 de julio de 2019.

"Felipe Kast: 'El talón de Aquiles de la derecha no es su respaldo a Pinochet, sino su falta de diversidad'”, La Tercera, 22 de diciembre de 2013.

"Felipe Kast: 'En un acto de genuflexión con la bancada estudiantil el gobierno le quitó piso a Eyzaguirre'”, La Tercera, 24 de julio de 2014.

“Felipe Kast, senador de Evópoli: 'La ciudadanía quiere ver a un Presidente que tome posición en temas tan importantes como identidad de género'", La Tercera, 1 de abril de 2018.

"Felipe Kast, ministro de Planificación: 'La izquierda no valora la movilidad social"”, The Clinic, 20 de octubre 2010.

"Felipe Kast: 'veo con preocupación a miembros de Chile Vamos tentados a girar a la extrema derecha", La Tercera, 15 de diciembre de 2018.

"Francisco Undurraga, diputado Evópoli: 'La diversidad de Chile Vamos no va a permitir asonadas populistas'”, La Tercera, 22 de octubre de 2018.

"Francisco Undurraga: 'Evópoli no va a vetar a nadie para llegar a acuerdos"”, La Tercera, 31 de diciembre de 2017.

"Hernán Larraín Matte, presidente de Evópoli: 'José Antonio Kast todavía es una noticia en desarrollo'”, La Tercera, 27 de abril de 2019.

Herrera, Hugo, "Dos derechas", La Tercera, 24 de junio de 2020. "José Antonio Kast: 'Este es un gobierno al que le falta carácter, y cuando a uno le pasa eso, cae en la ambigüedad'", La Tercera, 12 de octubre de 2018.

Kast, Felipe, Programa de gobierno del candidato a la presidencia Felipe Kast S. 2018-2022. Principales acciones, iniciativas y proyectos, 2017, https://www.servel.cl/wpcontent/uploads/2017/05/Pro gramaGobiernoFelipeKast_mayo2017.pdf 
Kast, José Antonio, “2019”, El Líbero, 1 de enero de 2019.

KAst, José Antonio, “¿Adiós carnaval? ¿Adiós general?”, The Clinic, 18 de febrero de 2018.

KAst, José Antonio, "Lanzado mi candidatura a la presidencia de la UDi es hasta el final”, La Segunda, 3 de junio de 2008.

KAst, José Antonio, "Carta de Renuncia a la UDI", 2016, https:// www.facebook.com/notes/jos\%C3\%A9-antonio-kast/cartade-renuncia-a-la-udi/1015064368585389/

Kast, José Antonio, Un programa para volver a creer, Programa de elección presidencial, 2017, https://www.servel.cl/programasde-candidaturas-a-presidente-de-la-republica/

Partido Republicano, "Declaración deprincipios", https:/ / www.24horas. $\mathrm{cl} /$ incoming/article3372081.ece/BINARY/ESTATUTOS\%20 DEFINITIVOS $\%$ 20PARTIDO \% 20REPUBLICANO $\% 20 \mathrm{VF} \%$ 2007-06-2019.pdf

Rumié, Sebastián, Stéphanie Alenda y Joaquín Fernández, "Transformaciones y continuidades: las sensibilidades de la derecha chilena”, CIPER, 24 de junio de 2020.

Schwember, Felipe, "Peronismo chileno", La Segunda, 3 de junio de 2020.

SERVEL, https://www.servel.cl/elecciones-anteriores/

UDI, "Declaración de principios", http://www.udisantiago.cl/documen tos/dec_princip.pdf 